\title{
Improved Alcohol Level Sensing Device that Transmit Offender's Data to a Central Server through Short Messaging Services (SMS)
}

\author{
B .I. Bakare, A. Umoru, and S. Orike
}

\begin{abstract}
This paper is an improved alcohol level sensing system, that measures alcohol intakes, display percentage of alcohol, sound an alarm if alcohol percentage is above the preset thresh hood, documents offender's data via keypad and transmit same data to a central server with SIM800 GSM/GPRS module via short messaging services for proper documentation and persecution purpose. Here we used an alcohol sensor circuit along with LCD display, a buzzer alarm, ATmega328 microcontroller, keypad and GSM sim module. The system first uses the alcohol sensor in order to detect the alcohol. The sensor provides analog input. These analog inputs are sent to the microcontroller for further processing. The microcontroller calculates the percentage of alcohol from the analog input received and displays the same on the LCD screen. The device was observed to sound an alarm when the percentage of alcohol exceeded the preset value of $0.05 \mathrm{~g} / \mathrm{mL}$. Through the use of a $4 \times 4$ keypad, documentation of the driver license serial number, the car plate number and name of the driver was achieved. These documented details of the erring driver were transmitted to a preprogrammed mobile phone number via SMS using the SIM800 GSM/GPRS module.
\end{abstract}

Index Terms - BAC, BrAC, ATMega328P, MQ3.

\section{INTRODUCTION}

Man has been consuming alcohol ever since he learned how to brew, ferment and concoct alcoholic beverages. In Nigeria, alcohol consumption is most prevalent in the southern regions of the country due to traditional, cultural, and religious beliefs. Due to the prevalence of alcohol consumption, drinking while driving and driving while being drunk has created a serious road safety challenge all over the world. According to a report by the European Transport Safety Council in 2012 [1], alcohol consumption accounts for about one-third of death and disability injuries from road traffic accidents. There is, therefore, the need for systems to checkmate the blood alcohol concentration of both private and commercial drivers.

Alcohol consumption is common to several cultures, traditions, and peoples of the world [2]. Blood alcohol concentration is the amount of alcohol in the bloodstream. It is measured in grams of ethanol per deciliter of blood $(\mathrm{g} / \mathrm{fdl}$, commonly used in the United States of America), or milliliters of blood, $(\mathrm{mg} / \mathrm{ml}$, used in much of Europe). BAC level above 0.5 is considered unsafe for driving and could result in drivers feeling dazed/confused or disoriented.

Published on September 8, 2020.

B. I. Bakare, Rivers State University, Nigeria.

(e-mail: bakare.bodunrin@ust.edu.ng).

A. Umoru, Rivers State University, Nigeria.

(e-mail: wahabino4great ${ }^{@}$ yahoo.com)
Blood alcohol concentration has been studied for about a century and it has been found that there is some correlation between blood alcohol concentration (BAC) and breath alcohol concentration (BrAC). Owing to this, $\mathrm{BrAC}$ is widely used in determining $\mathrm{BAC}$ of drivers by road traffic law enforcement as it is less invasive [3]. In Nigeria, the legal BAC limit is set at $0.5 \mathrm{~g} / 100 \mathrm{~mL}$ blood alcohol concentration (BAC), any level above that is said to be illegal.

A handheld alcohol sensing display is one of such systems which can effectively be employed to manage and curtail the challenge of drunk driving. The proposed device is design based on the ATMega 328P microcontroller. This device is made of three main sections; the power supply section which consists of a $6 \mathrm{~V}$ rechargeable battery. This unit provides DC voltage needed to power the microcontroller. The Sensing Unit and Display Unit primarily consist of the alcohol sensor (MQ3), a 16x2 LCD screen, the microcontroller, a $5 \times 4$ keypad and a GSM/GPRS module. The alcohol sensor detects alcohol in its surrounding air and sends relays it to the microcontroller via an ADC pin. The microcontroller calibrates the alcohol level into percentage and carries out corresponding actions based on this percentage. The GSM/GPRS module is used in sending the details of the driver via electronic mail or SMS protocol to the relevant authority. The display unit is made up of a 16X2 LCD display screen. It displays the percentage of alcohol present.

Cellular Systems use a technique known as frequency Reuse. A Particular available channel frequency is transmitted from a Base station at a power level that supports communications within a moderate cell radius around that Base station. Because this transmitted signal power is controlled to serve only a limited range, the same frequency can be transmitted simultaneously, or reused, by another Base station, provided there is no interference between it and any other base station using the same frequency [4].

\section{Human Physiology, BREATHING AND ITS INTERACTION WITH ALCOHOL}

Alcohol is typically ingested orally into the body by consumption of food or drinks which contain the chemical compound ethyl alcohol. It then passes from the oral cavity into the stomach and then the small intestine from where it enters the bloodstream by means of diffusion. This alcohol in the bloodstream is transported to other parts of body. This blood containing alcohol is carried to the lungs for

S. Orike, Rivers State University, Nigeria.

(e-mail: sunny@ust.edu.ng) 
oxygenation. This oxygenated blood is transported to the brain and the rest of the body.

Lung tissues are made of alveoli (air pockets) which are surrounded by blood-rich membranes. Some of the alcohol circulating in the lungs passes through these membranes and are evaporated into the alveoli. During exhalation, air is forced out of the alveoli emerging from the lungs into one's breath. Since air emerges from the mouth/nasal area, the throat, upper airway, and the lungs, when a person exhales completely, the "deep" lung air leaves the lungs last and would contain alcohol if alcohol has been ingested by that person.

Theoretically, the breath alcohol concentration can be determined by equation (1):

$\mathrm{EBAC}=\left(\frac{0.806 \times \mathrm{SD} \times 1.2}{\mathrm{BW} \times \mathrm{WT}}-\mathrm{MR} \times \mathrm{DP}\right) \times 10$

where:

EBAC $=$ Estimated Blood Alcohol Concentration;

$0.806=$ Constant for body water in blood;

$\mathrm{SD}=$ Number of standard drinks that being $10 \mathrm{~g}$ of ethanol each. $=1.4$ for $375 \mathrm{ml}$ of Beer containing $5 \%$ alcohol;

$1.2=$ Factor to convert amount in grams to Swedish standard;

$\mathrm{BW}=$ Body water constant (0.58 for males, 0.49 for females);

WT= Body weight $(\mathrm{kg})$;

$\mathrm{MR}=$ Metabolism constant $(0.015$ for males, 0.017 for females);

$\mathrm{DP}=$ Drinking period (In Hours);

$10=$ Conversion constant to convert to percentage of alcohol.

\section{MATERIALS AND METHODS}

The improved handheld alcohol level sensing display developed in this work consists of several electronic components with each component performing a specific task in the circuit setup. The improved handheld alcohol level sensing and display device implemented in this work is made up of three sections. The three sections are: (a) Power Supply, (b) Sensing and Processing Unit (SPU), (c) Display Unit.

\section{A. Power Supply}

This unit supplies 6V DC power required for the entire system to function. It consists of 6V DC rechargeable battery, and USB 2.0 connector. This unit is designed so as to enable charging of the device to be carried out independent of power grid.

\section{B. Sensing and Processing Unit}

This unit houses the ATmega 328p microcontroller, the MQ-3 alcohol gas sensor, buzzer alarm, a 5x4 keypad and a GSM/GPRS module.

\section{i. MQ 3 Gas Sensor}

In semiconductor gas sensor, electrical conductivity (or resistance) varies with the physical adsorption of gas molecules. Generally, the electrical conductivity of a semiconductor material $\sigma$ is proportional to the concentration of the carrier, $n_{e}$. This relationship can be expressed mathematically as shown in equation (2).

$\sigma \propto n_{e}$
As shown in (3) the concentration of the carrier electrons of the semiconductor material is related to the band gap energy $E_{g}$ between the valence band and the conduction band. $n_{e} \propto e^{-\beta E_{g}}$,

$\beta=\frac{1}{K_{B} T}$

where:

$K_{B}$ is the Boltzmann's constant.

$\mathrm{T}$ is the temperature.

Thus, (2) can be expressed in the form as shown in (5).

$\sigma=\sigma_{s} e^{-\beta E_{g}}$

where:

$\sigma_{S}$ is a constant of proportionality.

The alcohol gas sensor (MQ-3) is composed of $\mathrm{SnO}_{2}$ as its sensitive material. This sensor has a high sensitivity to alcohol and very low sensitivity to benzene, vapor, petrol, $\mathrm{CO}_{2}$, methane, hexane, propane, and other gases.

This sensor has a low conductivity in clean air and upon exposure to alcohol, its conductivity increases. This conductance is sent to an ADC pin of the microcontroller through a $10 \mathrm{~K}$ resistor and a $10 \mathrm{~K}$ potentiometer connected in parallel on the sensor module. The microcontroller converts these received bytes to percentage concentration in $\mathrm{mg} / \mathrm{ml}$. This concentration can be read from both the digital output and the analog output of a microcontroller. The MQ3 is highly sensitive to alcohol and can accurately measure from $0.05 \mathrm{mg} / \mathrm{L}$ to $10 \mathrm{mg} / \mathrm{L}$ of alcohol concentration.

Considering the adsorption of gas molecules on the surface of the semiconductor, for a small amount of adsorption, the effect of the adsorption on the width of the band gap is so small that we can treat the adsorption as a perturbation of the semiconductor. From the quantum mechanical theory of perturbation, the band gap changes as the expression below:

$E_{g} \rightarrow E_{g}+\varepsilon$

With the first order effect, $\varepsilon$, is proportional to the perturbation strength. Thus, the number of gas molecules $\mathrm{N}$, adsorbed by the sensor can be obtained by the expression in (6).

$\varepsilon=c N$

Where $\mathrm{c}$ is a constant of proportionality which value depends on the identity of the adsorbed molecules $\sigma_{a}$.

Therefore, the electrical conductivity of the semiconductor gas sensor in respect to the adsorbed molecules $\sigma_{a}$ can be expressed as:

$\sigma_{a}=\sigma_{s} e^{-\beta\left(E_{g}+\varepsilon\right)}$

$\sigma_{a}=\sigma e^{-c \beta N}$

Therefore, from (9) the change in conductivity which is due to adsorption $S_{\sigma}$ is proportional to the number $\mathrm{N}$ of adsorbed molecules and depends on the identity of the adsorbed molecules. 


$$
\begin{aligned}
& S_{\sigma}=\frac{\sigma_{a}-\sigma}{\sigma} \\
& =\sigma^{-\beta \varepsilon}-1 \\
& \cong-\beta \varepsilon \\
& S_{\sigma}=-c \beta N
\end{aligned}
$$

Considering (11) to be time dependent, with the number of adsorbed molecules varying with time, $S_{\sigma}$ can be expressed as:

$S_{\sigma}(t)=a N(t)$

Where $a=-c \beta$.

\section{ii. GSM/GPRS Module}

A GSM/GPRS module is a device which can be used in accessing or connecting to mobile phone network providers in order to make calls, send SMS and also connect to the internet. These devices make use of several protocols such as UART, USART, and AT Commands in executing these tasks. For the purpose of this work, a SIM899A GSM/GPRS module is used in sending the BrAC sensed by the MQ3 alcohol sensor to designated email address or mobile phone numbers. "SIM800 is a quad-band GSM/GPRS module that works on frequencies GSM 850MHz, EGSM 900MHz, DCS $1800 \mathrm{MHz}$ and PCS $1900 \mathrm{MHz}$. SIM800 features GPRS multislot class 12/ class 10 (optional) and supports the GPRS coding schemes CS-1, CS-2, CS-3 and CS-4" [5] ,[6]. The SIM800A is set in SMS mode and connected to the World Wide Web using AT Command. The SIM800 GSM/GPRS module is connected to pins 15 and 16 of the ATMega 328 microcontroller.

\section{iii. Buzzer}

A buzzer is a two terminal device that produces sound when current is passed through it. The long terminal being the anode and the short terminal the cathode. The anode is connected to pin 27 (PC4) which is the digital pin 3 of the ATmega328p controller board and the cathode connected to the common ground. Its switching is controlled by digital pulses of HIGH (Logic 1) or LOW (Logic 0). In this work, it also serves as an indication for BrAC. The buzzer is triggered when the BrAC exceeds that which is preset in the program.

\section{iv. ATMega $328 P$}

The microcontroller governs the entire functions and operation of this device. It houses the source code carries out corresponding actuation depending on the reading from the alcohol gas sensor. It also controls the LCD display. The ATmega328p is a high performance, low power consuming 8bit, AVR microcontroller.

\section{Display Unit}

The display unit comprises of a 16x2 LCD screen and a $10 \mathrm{~K}$ potentiometer for contrast control of the LCD. The LCD is powered by the same $5 \mathrm{~V}$ DC used in powering the controller. Six pins of the LCD are connected to the controller, namely pins; E, RS, 11, 12, 13, 14. The LCD screen indicates at all times the $\mathrm{BrAC}$ percentage calculated by the microcontroller.
TABLE I : LCD TO ATMEGA328P CONNECTION

\begin{tabular}{cc}
\hline \hline LCD Pin & AT Mega 328p Pin \\
\hline VSS & $8(\mathrm{GND})$ \\
VDD & $7(5 \mathrm{~V})$ \\
VO & 25 \\
RS & $8(\mathrm{GND})$ \\
RW & 24 \\
E & Not connected \\
D0 & Not connected \\
D1 & Not connected \\
D2 & Not connected \\
D3 & 23 \\
D4 & 19 \\
D5 & 18 \\
D6 & 17 \\
D7 & $7(5 \mathrm{~V})$ \\
A & $8(\mathrm{GND})$ \\
K
\end{tabular}

\section{Circuit Design}

A suitable circuit is designed in the development of the improved alcohol level sensing and display device. The circuit is designed on a vero board interface, with each component carefully connected and soldered on the board. The size of the entire circuit is designed so as to make the device portable considering its intended application. The circuit layout designed for this work can be seen in Fig. 1. The ATmega 328P is first programmed on an Arduino Uno R3 and then transferred to the vero board interface where it is mounted on IC sockets. Considering that a range of values are required to properly calibrate the device, the analog output of the MQ3 sensor is connected to pin 24 of the microcontroller.

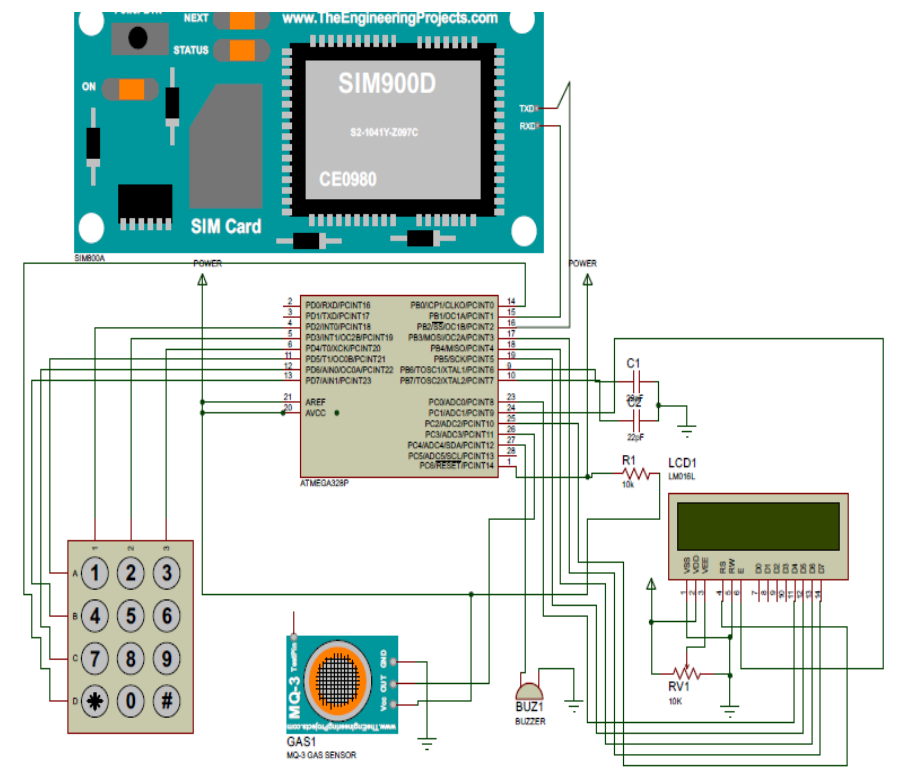

Fig.1. Device Circuit Diagram.

\section{E. Software Development}

The software which governs the alcohol sensing and display device is developed using the AVRISPll programmer on the Arduino 1.8.6 Integrated Development Environment (IDE). This IDE was chosen due to its availability, easy of programming and its open source access. The Arduino bootloader is first uploaded to the ATmega328p microcontroller in order to make it compactable with the IDE. This is done by selecting the ArduinoISP sketch from the examples folder on the Arduino IDE and uploading to the 
board. The program is designed such that a variable name "mq3" is assigned for the MQ3 alcohol gas sensor. A variable location "alcohol" is declared and the values of the MQ3 sensor output is read into this location. This reading is then calibrated and read to a floating variable location "tox". This gives the corresponding BrAC in $\mathrm{mg} / \mathrm{L}$. The value of "tox" is displayed on the screen of the $16 \times 2$ lcd. The block diagram used in the development of the program code are shown in Fig. 2 and Fig. 3 below.

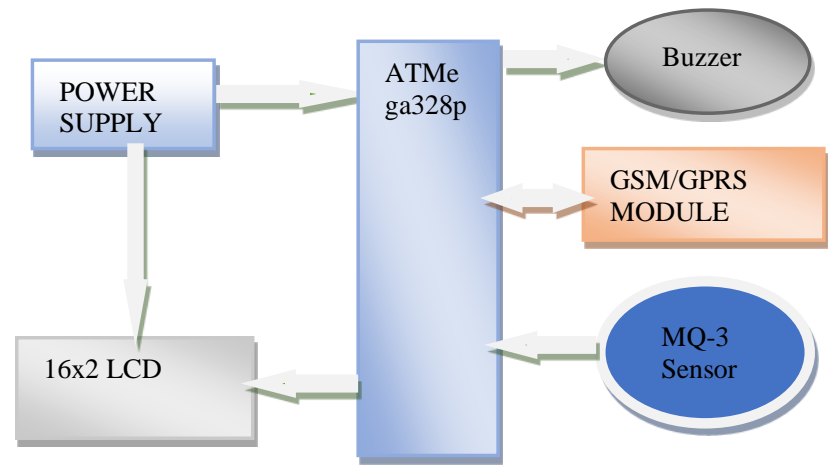

Fig. 2. System Block Diagram.

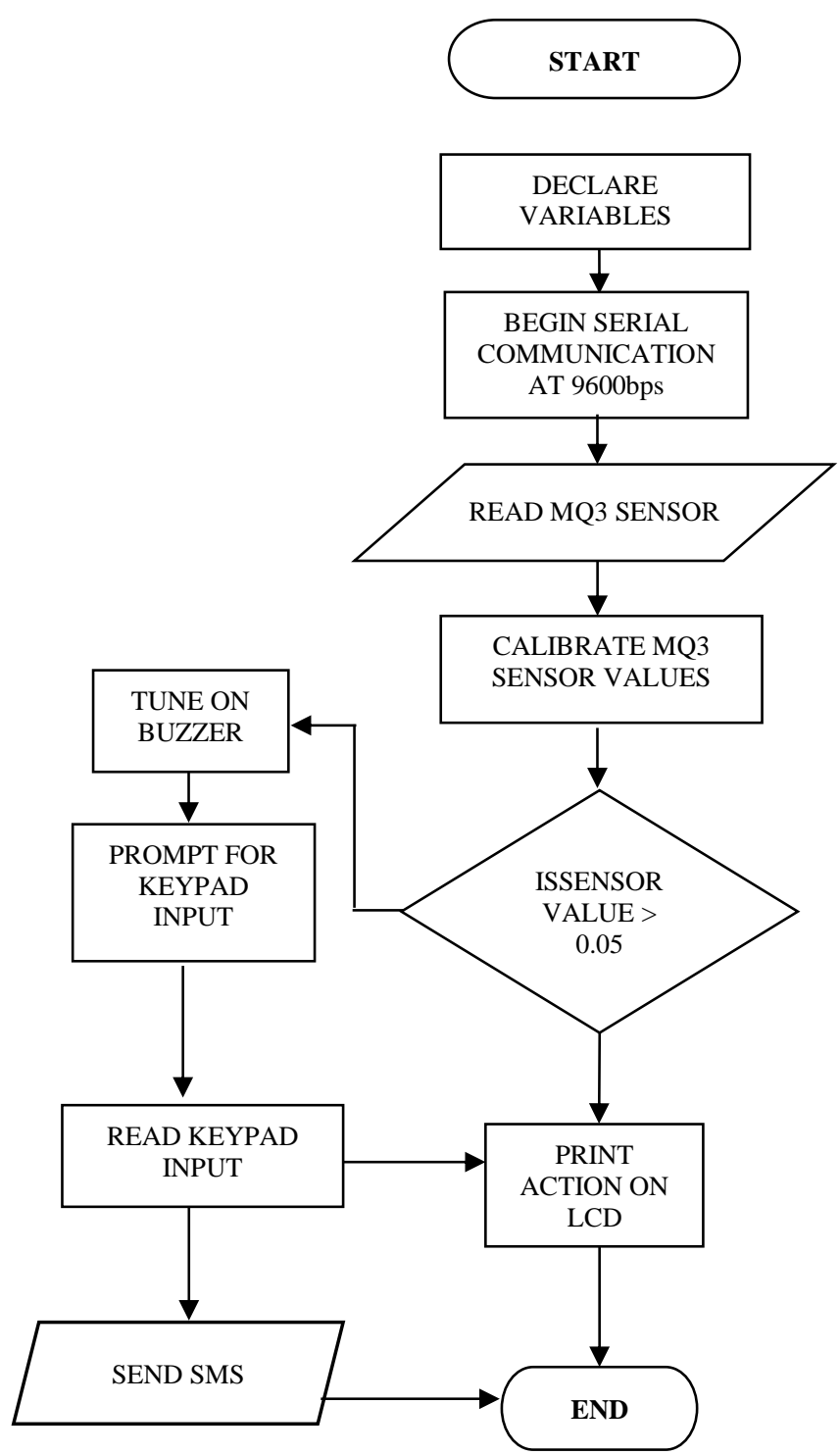

A. Results

The MQ3 alcohol gas sensor when connected to the Arduino analog input and exposed to alcohol, generated values in the form of bytes ranging from 0-1023 as shown in Fig. 4 and Fig. 5 below.

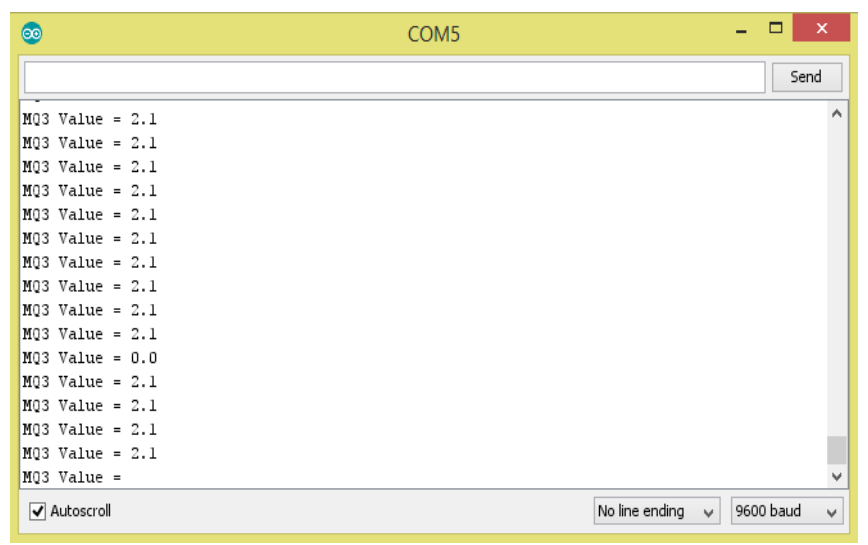

Fig. 4. MQ3 Sensor alcohol measurement in Air

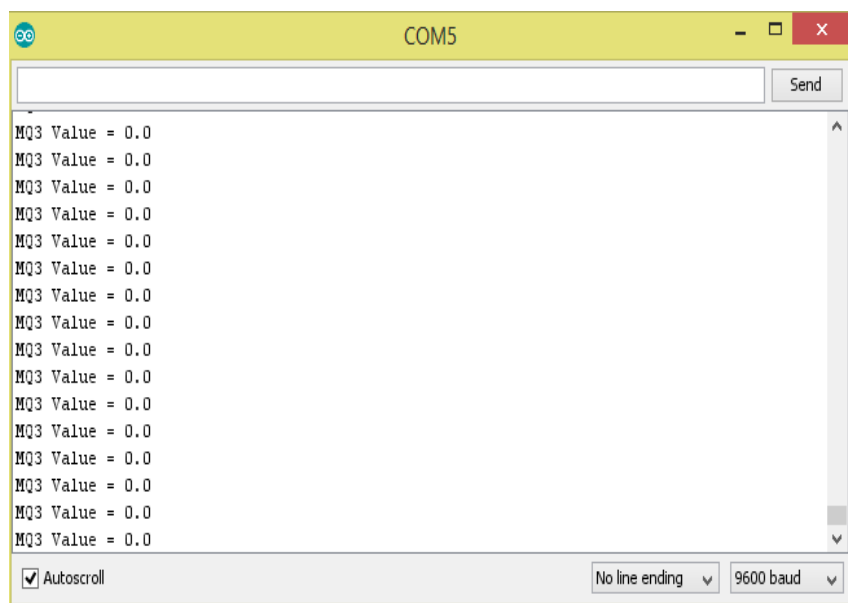

Fig. 5. MQ3 Sensor Raw Data after Consuming One Bottle of 5\% Beer.

These data cannot be used in this form as it does not tally with any existing BrAC chart. Thus, the need for proper sensor calibration in order for the sensor's output data to be useable. In calibrating the alcohol sensor, the expression in (1) is used.

TABLE II: ESTIMATED BLOOD ALCOHOL CONCENTRATION (EBAC1) FoR

\begin{tabular}{ccccc}
\multicolumn{5}{c}{ A 65 KG MALE IN ONE HouR } \\
\hline \hline $\begin{array}{c}\text { No of } \\
\text { Bottles }\end{array}$ & $\begin{array}{c}\text { No of Standard } \\
\text { Drink (375ml } \\
\text { of 5\% Beer) }\end{array}$ & $\begin{array}{c}\text { Drinking } \\
\text { Period } \\
\text { (Hours) }\end{array}$ & $\begin{array}{c}\text { Total } \\
\text { Standard } \\
\text { Drink }\end{array}$ & $\begin{array}{c}\text { EBAC } \\
(\mathrm{mg} / \mathrm{L})\end{array}$ \\
\hline 1 & 1.4 & 1 & 1.4 & 0.021 \\
2 & 1.4 & 1 & 2.8 & 0.057 \\
3 & 1.4 & 1 & 4.2 & 0.093 \\
4 & 1.4 & 1 & 5.6 & 0.129 \\
5 & 1.4 & 1 & 7 & 0.165 \\
6 & 1.4 & 1 & 8.4 & 0.201 \\
7 & 1.4 & 1 & 9.8 & 0.236 \\
8 & 1.4 & 1 & 11.2 & 0.272 \\
9 & 1.4 & 1 & 12.6 & 0.308 \\
10 & 1.4 & 1 & 14 & 0.344 \\
\hline \hline
\end{tabular}

Fig. 3. System Flowchart Algorithm. 
TABLE III: ESTIMATED BLOOD ALCOHOL CONCENTRATION (EBAC2) FoR A 65 KG MALE In Two Hour

\begin{tabular}{ccccc}
\hline $\begin{array}{c}\text { No of } \\
\text { Bottles }\end{array}$ & $\begin{array}{c}\text { No of Standard } \\
\text { Drink (375ml } \\
\text { of 5\% Beer) }\end{array}$ & $\begin{array}{c}\text { Drinking } \\
\text { Period } \\
\text { (Hours) }\end{array}$ & $\begin{array}{c}\text { Total } \\
\text { Standard } \\
\text { Drink }\end{array}$ & $\begin{array}{c}\text { EBAC } \\
\text { (g/dL) }\end{array}$ \\
\hline 1 & 1.4 & 2 & 1.4 & 0.0059 \\
2 & 1.4 & 2 & 2.8 & 0.05 \\
3 & 1.4 & 2 & 4.2 & 0.08 \\
4 & 1.4 & 2 & 5.6 & 0.11 \\
5 & 1.4 & 2 & 7 & 0.15 \\
6 & 1.4 & 2 & 8.4 & 0.19 \\
7 & 1.4 & 2 & 9.8 & 0.22 \\
8 & 1.4 & 2 & 11.2 & 0.26 \\
9 & 1.4 & 2 & 12.6 & 0.29 \\
10 & 1.4 & 2 & 14 & 0.33 \\
\hline \hline
\end{tabular}

TABLE IV: COMPARING MQ3 DATA AND EBAC

\begin{tabular}{cccc}
\hline \hline EBAC1 & $\begin{array}{c}\text { SENSOR } \\
\text { OUTPUT }\end{array}$ & EBAC2 & SENSOR OUTPU \\
\hline 0.021 & 2.1 & 0.0059 & 0.6 \\
0.057 & 5.8 & 0.05 & 5.1 \\
0.093 & 9.5 & 0.08 & 8.1 \\
0.129 & 13.1 & 0.11 & 11.2 \\
0.165 & 16.8 & 0.15 & 15.3 \\
0.201 & 20.5 & 0.19 & 19.4 \\
0.236 & 24.1 & 0.22 & 22.5 \\
0.272 & 27.8 & 0.26 & 26.5 \\
0.308 & 31.5 & 0.29 & 29.6 \\
0.344 & 35.1 & 0.33 & 33.7 \\
\hline \hline
\end{tabular}
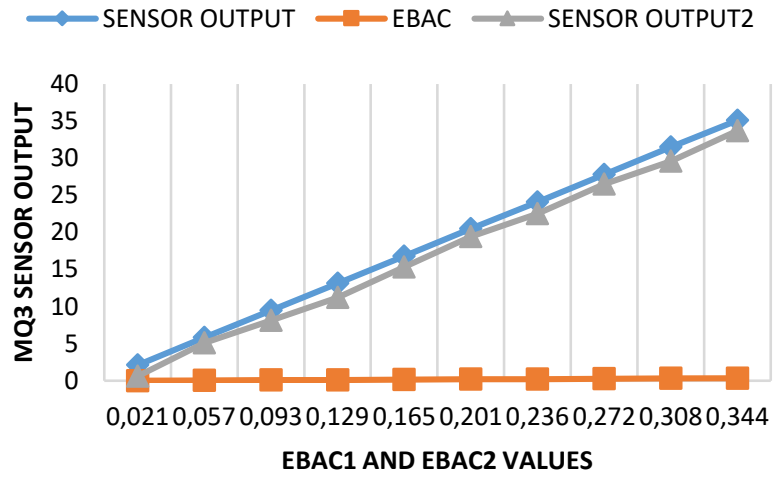

Fig. 6. Comparing Mq3 Raw Output Values with Ebac Values.

\section{B. Discussion}

The improved alcohol level sensing device with display, alarm, GPRS/SIM module, alphanumeric keypad, 5v battery and microcontroller developed in this work is a portable, easy to carry and an easy to use device that could be applied in the most remote of places. The portability of this device is due to its size. Thus, it could easily be carried about. This makes this device highly implementable in highways across the country as no special training, equipment and carriage is required for the device to be operated.

It is observed that when one exhales through the mouth into the sensor, the corresponding BrAC is displayed on the LCD screen. When the BrAC is less than 0.05, the buzzer stays OFF and BrAC level is displayed on the LCD screen. therwise, the buzzer is turned $\mathrm{ON}$, the corresponding $\mathrm{BrAC}$ is displayed on the LCD with the string "ENTER LICENSE" activating the $5 \times 4$ keypad for the operator to enter the driver's license, driver's name and vehicle plate number. When a key is pressed on the keypad, its corresponding value is displayed on the LCD screen. Any of these call-up functions can be terminated by pressing the F4 key on the $5 \times 4$ keypad. Key '\#' is used in switching the keypad function form alphabet to numeric and vice versa. When data entry is completed, the LCD is observed to print "SENDING SMS" and "SENDING EMAIL". An SMS is received by the designated phone number within a minute.

The ease of use, interpretation and detection of drunken state by this device is due to the use of a display interface (16x2 LCD) which shows the exact alcohol concentration in an individual's breath. This makes it easier for documentation for the appropriate persecution by road traffic officers.

This system is user friendly as it requires no special skill fowledge to interpret and confirm a driver as having consumed more than the stipulated amount of alcohol. This is due to the buzzing of the alarm whenever the alcohol concentration is found to have exceeded $0.05 \mathrm{mg} / \mathrm{L}$. Thus, this device is suitable in monitoring of drivers to ensure and enforce compliance of the prohibition on drunk driving. A complete implementation of this device by road traffic officers across the country would reduce the number of road accidents which are caused by drunk driving.

\section{CONCLUSION}

Improved alcohol level sensing devices or breathalyzers as they are commonly called are devices that are used in determining the percentage Breath Alcohol Concentration of individuals. These devices usually make use of specially designed gas sensors in detecting BrAC.

In this work, an improved alcohol sensing device with display was developed. This device uses the MQ3 sensor in detecting BrAC levels of drivers. This device was developed for use by law enforcement agencies to checkmate the menace of drunk driving. The device consists of an Atmega328 microcontroller, a buzzer alarm, an MQ3 alcohol gas sensor, a GSM/GPRS module, a 5x4 keypad and a 16X2 LCD screen.

The MQ3 sensor is a transducer used in this work in sensing breath alcohol concentration. This sensor was capable of effectively sensing breath alcohol concentration level of $0.05-10 \mathrm{~g} / \mathrm{mL}$.

The system was designed such that, BrAC levels exceeding $0.05 \%$ are considered to be above the limit. At such instances, the buzzer alarm is turned on, with the BrAC displayed on the LCD.

Through the use of a $4 \times 4$ keypad, documentation of the driver license serial number, the car plate number and name of the driver was achieved.

These documented details of the erring driver are thus transmitted to a preprogrammed mobile phone number via SMS using a SIM800 GSM/GPRS module.

Thus, this system was able to satisfy its intended aim of identification of breath alcohol concentration, documentation of data of erring drivers and collation of this data to a central source via SMS. 


\section{APPENDIX}

Appendix A: PROGRAM

\#include<LiquidCrystal.h>

\#include <SoftwareSerial.h>

SoftwareSerial mySerial $(10,11)$;

char msg;

char number;

char number1;

const int $\mathrm{mq} 3=\mathrm{A} 0$;

float alcohol $=0$;

float tox;

int $\operatorname{maxi}=1023$;

int mini $=0$;

const byte ROWS $=4$; //four rows

const byte $\mathrm{COLS}=4$; //three columns

char keys[ROWS][COLS] $=\{$

$$
\begin{aligned}
& \text { \{'1','2','3','A' \}, }
\end{aligned}
$$

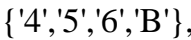

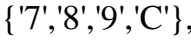

$$
\begin{aligned}
& \left\{' * ',{ }^{\prime} 0\right. \text { ','\#','D'\} }
\end{aligned}
$$

\} ;

$/ *$ byte rowPins[ROWS $]=\{8,7,6,5\} ; / /$ connect to the row pinouts of the keypad

byte colPins $[$ COLS $]=\{11,10,9\}$; //connect to the column pinouts of the $\operatorname{keypad} * /$

byte rowPins[ROWS $]=\{2,3,4,5,6\} ; / /$ connect to the row pinouts of the keypad

byte colPins $[$ COLS $]=\{6,7,8,9\}$;

LiquidCrystal lcd $(12,13,14,15,16)$;

int buzzer $=17$;

void $\operatorname{setup}()$

\{

pinMode(17,OUTPUT);

Serial.begin(9600);

mySerial.begin(9600);

lcd.begin(16,2); // put your setup code here, to run once:

\}

void $\operatorname{loop}()$

\{

alcohol =analogRead(mq3);

Serial.print("alcohol=");

Serial.println(alcohol);

delay (200);

tox $=(($ alcohol/1023)/460 $) * 10$;

Serial.print("It alcohol=");

Serial.println(tox);

lcd.setCursor $(0,0)$;

lcd.print(" $\mathrm{BrAC}=$ ");

lcd.setCursor $(0,6)$;

lcd.print(tox);

if $($ tox $>=0.05)\{$

\}

\}

void sendMessage ()\{

mySerial.println("AT+CMGF=1"); delay(1000);

mySerial.println("AT+CMGS=|"+2348036660873।"\r"); delay(1000);

mySerial.write(BrAC);

delay(1000);

mySerial.println((char)26);

delay(1000);
Serial.println("sent");

delay(1000);

\}

void sendMail()

\}

\section{REFERENCES}

[1] European Transport Safety Council (2012). Drink Driving: Towards Zero Tolerance [Online], available at https://etsc.eu/wpcontent/uploads/2014/02/Drink_Driving_Towards> Zero_Tolerance.pdf.

[2] G. Gasparesc (2018). Driver Alcohol Detection System Based on Virtual Instrumentation. IFAC PapersOnLine 51-6 (2018) 502-507. Available online at www.sciencedirect.com.

[3] A. W. Jones, The Relationship between Blood Alcohol Concentration (BAC) and Breath Alcohol Concentration (BrAC): A Review of the Evidence. Road Safety Web Publication, vol. 15, 1-43, 2010.

[4] B.I. Bakare, I.A. Ekanem and I.O Allen. Appraisal of Global System for Mobile Communication (GSM) in Nigeria, American Journal of Engineering Research (AJER) e-ISSN: 2320-0847 P-ISSN: 23200936.Vol-6, Issue-6, pp-97-102, 2017.

[5] SIMCOM (2016). SIM800 Hardware Design V1.09. http://mtsystem.ru/sites/default/files/documents/sim800_hardware_design_v1. 09.pdf.

[6] Oloyede, M. A., Michael, D., and Waheed, M. A. (2018). Alcohol Detecting and Notification System for Controlling Drink Driving. 2nd International Conference on Information and Communication Technology and Its Applications (ICTA 2018), Federal University of Technology, Minna, Nigeria September 5-6, 2018.

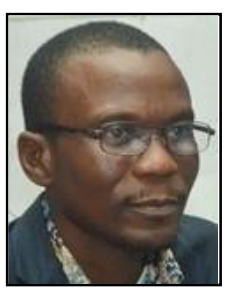

B. I. Bakare holds a Bachelor of Engineering (B.Eng.) Degree in Electrical Engineering; from Ondo State University, Ado Ekiti, (Now University of Ado Ekiti, Ekiti State), Master of Engineering (M.Eng.) Degree in Electrical/Electronic Engineering from University of Port Harcourt, Nigeria and he is currently a $\mathrm{PhD}$ (Communication Engineering) Researcher of Nnamdi Azikiwe University (Unizik), Awka, Anambra State. He holds a Category One Electrical Wiring License. $\mathrm{He}$ is a COREN registered Engineer, a Corporate Member of Nigeria Society of Engineers (NSE), a member of International Association of Engineers (I A ENG) and an active member of Nigeria Institute of Electrical and Electronics Engineers (NIEEE). He is presently a lecturer in the Department of Electrical Engineering, Rivers State University, Port Harcourt., Nigeria. He is married and has children.

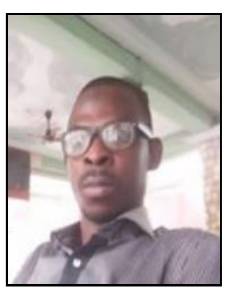

A. Umoru holds a Bachelor of Technology (B.Tech) degree in Electrical Engineering (Electronics option) from the Ambrose Ali University, Edo State, Nigeria and he is currently an M.Tech (Electronics Engineering Option) Researcher of the Rivers State University, Nkpolu Oruworukwo, Rivers State.

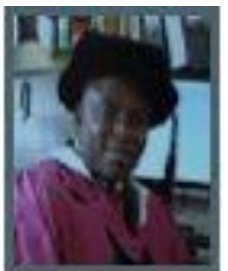

S. Orike received his B. Tech. in Computer Engineering from Rivers State University of Science and Technology (now Rivers State University); M.Sc. in Computing and M.Phil. in Computational Intelligence, both from Robert Gordon University, Aberdeen, United Kingdom; and Ph.D in Artificial Intelligence from HeriotWatt University, Edinburgh, United Kingdom. Dr. Orike is an active member of several professional bodies, including Council for the Regulation of Engineering in Nigeria, Nigeria Institution of Electrical Electronic Engineers and International Association of Engineers. He is a Senior Lecturer and currently the Head, Department of Computer Engineering, Rivers State University, Port Harcourt, Nigeria. Dr. Orike has published in several reputable journals, presented at both local and international conferences, and acts as a reviewer to several journals. He is a Facilitator with the National Open University of Nigeria, and External Assessor for Port Harcourt Polytechnic, Nigeria. He is married and has children. 